\title{
Expression of SOX9 Is Related to Prognosis in Patients with Oesophageal Squamous Cell Carcinoma
}

\author{
NAOTOMO HIGO, HIROSHI OKUMURA, YASUTO UCHIKADO, ITARU OMOTO, KEN SASAKI, YOSHIAKI KITA, \\ DESAKI RYOSUKE, MASAHIRO NODA, TETSUHIRO OWAKI, SUMIYA ISHIGAMI and SHOJI NATSUGOE \\ Department of Surgical Oncology, Digestive Surgery, \\ Graduate School of Medicine, Kagoshima University, Kagoshima, Japan
}

\begin{abstract}
Background: Sex-determining region Y-box 9 (SOX9) is an important transcription factor for the development and differentiation of cells and their organization. In the present study, the clinical significance of SOX9 expression in oesophageal squamous cell carcinoma was examined. Materials and Methods: SOX9 expression in surgical specimens of primary tumours were immunohistochemically investigated in 175 patients with oesophageal squamous cell carcinomas. Results: SOX9 was expressed (moderately or strongly) in $62.9 \%$ of samples. Expression of SOX9 was significantly positively correlated with depth of invasion, advanced stage, lymphatic and venous invasion, and poor prognosis. Univariate analysis showed that depth of invasion, lymph node metastasis, distant metastasis, stage, lymphatic invasion, venous invasion, and SOX9 expression were prognostic factors. Multivariate analysis indicated that depth of invasion and stage were independent prognostic factors, but SOX9 expression was not. Conclusion: SOX9 expression is related to prognosis in patients with oesophageal squamous cell carcinoma, although it is not an independent prognostic factor.
\end{abstract}

Oesophageal squamous cell carcinoma (ESCC) is one of the most aggressive carcinomas of the gastrointestinal tract (1). There have been many studies of the effects of various biological factors on the malignant potential of ESCC. Sexdetermining region Y-box 9 (SOX9) is an important transcriptional factor for the development and differentiation of cells and their organization (2). Recently, there have been

This article is freely accessible online.

Correspondence to: Hiroshi Okumura, Department of Surgical Oncology, Digestive Surgery, Graduate School of Medicine, Kagoshima University, Sakuragaoka 8-35-1, Kagoshima 890-8520, Japan. Tel: +81 992755361, Fax: +81 992657426, e-mail hokumura@ m.kufm.kagoshima-u.ac.jp

Key Words: SOX9, oesophageal cancer, prognosis. reports of a correlation between SOX9 expression and clinical outcomes in some cancer types, including gastrointestinal tract cancer (3-9). The aims of this retrospective study were to examine the expression of SOX9 protein in surgical specimens from patients with ESCC treated with radical surgery and to evaluate whether such expression is useful for predicting their outcome.

\section{Materials and Methods}

Study groups. The study included 175 consecutive patients with ESCC who underwent curative surgery at Kagoshima University Hospital between 1996 and 2006. The patients ranged in age from 43 to 87 years (mean=63.3 years). All patients underwent oesophagectomy with lymph node dissection. None underwent endoscopic mucosal resection, palliative resection, preoperative chemotherapy, or radiotherapy, and none of them had synchronous or metachronous cancer in other organs. Specimens of cancer tissues and non-cancerous adjacent tissue were collected from the patients after informed consent had been obtained, in accordance with the institutional guidelines of our hospital. The specimens were classified according to the International Union against Cancer tumour-node-metastasis (TNM) system (10). All M1 classifications were due to distant lymph node metastases. All patients were followed-up after discharge with a radiographic examination every 1-3 months, computed tomography every 3-6 months, and ultrasonography every 6 months. Follow-up data were available for all patients, with a median follow-up period of 43 months (range $=2$ 181 months).

Immunohistochemistry. Tumour samples were fixed with $10 \%$ formaldehyde in phosphate-buffered saline (PBS), embedded in paraffin, and sectioned into $4-\mu \mathrm{m}$-thick slices. After deparaffinization of the sections, endogenous peroxidase was blocked by immersing the slides in a $0.3 \%$ hydrogen peroxidasemethanol solution for 30 minutes at room temperature. For staining with SOX9 antibodies, sections were pre-treated with citrate buffer for $10 \mathrm{~min}$ at $100^{\circ} \mathrm{C}$ in a microwave oven. The sections were washed three times with PBS for $5 \mathrm{~min}$, and then blocked by treatment with PBS containing 3\% skim milk for $30 \mathrm{~min}$ at room temperature. The blocked sections were incubated overnight at $4{ }^{\circ} \mathrm{C}$ with primary antibody: SOX9 (AB5535, Merck Millipore, Darmstadt Germany), diluted with PBS 1:500 before staining with 
a streptavidin-biotin peroxidase kit (Nichirei, Tokyo, Japan). The sections were washed three times in PBS for $5 \mathrm{~min}$, and the immune complex was visualized by incubating the sections with diaminobenzidine tetrahydrochloride. They were rinsed briefly in water, counterstained with haematoxylin, and mounted. The normal oesophageal epithelium tissues were used as the positive control, and negative controls were generated by replacing the primary antibodies with PBS.

Immunohistochemistry was independently evaluated by two investigators (N.H. and H.O.). To evaluate SOX9 expression, 10 fields of the tumour were selected, and expression was evaluated in 1,000 tumour cells (100 cells/field) using high-power $(\times 200)$ microscopy. For nuclear expression of SOX9, immunostaining of each section was scored on a 4-tiered scale for intensity: absent: $0 \%$ (Figure 1A), weak: less than 5\% (Figure 1B), moderate: 5-50\% (Figure 1C), and strong: $51-100 \%$ (Figure 1D). The protein expression was defined as positive when the intensity was moderate or strong.

Statistical analysis. Statistical analysis of group differences was performed using the chi-squared test and the $t$-test. The Kaplan-Meier method was used for survival analysis, and differences in survival were estimated using the log-rank test. The prognostic factors were examined by univariate and multivariate analyses (Cox proportional hazards regression model). The $p$-values in this study are from twosided tests, and a $p$-value of less than 0.05 was considered significant. All statistical analyses were performed using the SPSS Statistics Software Package (SPSS Inc., Chicago, IL, USA).

\section{Results}

SOX9 expression in ESCC. SOX9 expression was absent in $20.6 \%$ (36 cases), weak in $16.6 \%$ (29 cases), moderate in $30.9 \%$ (54 cases), and strong in $32.0 \%$ (56 cases). Thus, positive expression of SOX9 was detectable in nuclear regions in $62.9 \%$ of all patients (Figure 1, Table I).

Relationship between SOX9 expression and clinicopathological findings. SOX9 expression was significantly associated with depth of tumour invasion (pT), stage, lymphatic invasion, and venous invasion (Table I). Tumours with positive expression of SOX9 invaded deeper, were of a more advanced stage, with more frequent lymphatic or venous invasion $(p=0.0003$, $0.0003,0.018$ and 0.005 , respectively) than those that were negative for SOX9 expression.

Relationship between prognosis and SOX9 expression by univariate and multivariate analyses of survival. The postoperative survival rate was significantly better in patients with negative SOX9 expression than in those with positive SOX9 expression. ( $p=0.008$; Figure 2). Univariate analysis showed the following factors to be significantly related to poorer postoperative survival: depth of tumour invasion, lymph node metastasis, distant metastasis, stage, lymphatic invasion, venous invasion, and SOX9 expression. Multivariate regression analysis indicated that depth of tumour invasion and stage were independent prognostic factors (Table II).
Table I. Relationships between sex-determining region Y-box 9 (SOX9) expression and clinicopathological factors in patients with oesophageal squamous cell carcinoma.

\begin{tabular}{|c|c|c|c|c|}
\hline Characteristic & Total & $\begin{array}{l}\text { SOX9- } \\
\text { positive } \\
(n=110, \\
62.9 \%)\end{array}$ & $\begin{array}{c}\text { SOX9- } \\
\text { negative } \\
(\mathrm{n}=65, \\
37.1 \%)\end{array}$ & $p$-Value \\
\hline \multicolumn{5}{|l|}{ Age, years } \\
\hline Mean \pm SD & $63.3 \pm 8.8$ & $63.0 \pm 9.2$ & $63.7 \pm 8.1$ & 0.64 \\
\hline \multicolumn{5}{|l|}{ Gender, $\mathrm{n}$} \\
\hline Male & 162 & 102 & 60 & 0.92 \\
\hline Female & 13 & 8 & 5 & \\
\hline \multicolumn{5}{|l|}{$\mathrm{pT}, \mathrm{n}$} \\
\hline $\mathrm{pT} 1,2$ & 74 & 35 & 39 & 0.0003 \\
\hline $\mathrm{pT} 3,4$ & 101 & 75 & 26 & \\
\hline \multicolumn{5}{|l|}{$\mathrm{pN}, \mathrm{n}$} \\
\hline pNo & 65 & 35 & 30 & 0.058 \\
\hline $\mathrm{pN} 1$ & 110 & 75 & 35 & \\
\hline \multicolumn{5}{|l|}{$\mathrm{pM}, \mathrm{n}$} \\
\hline pM0 & 130 & 79 & 51 & 0.33 \\
\hline pM1 & 45 & 31 & 14 & \\
\hline \multicolumn{5}{|l|}{ Stage, $\mathrm{n}$} \\
\hline $\mathrm{I}, \mathrm{II}$ & 74 & 35 & 39 & 0.0003 \\
\hline III, IV & 101 & 75 & 26 & \\
\hline \multicolumn{5}{|l|}{ Histology, $\mathrm{n}$} \\
\hline Well, moderate & 145 & 92 & 53 & 0.72 \\
\hline Poor & 30 & 18 & 12 & \\
\hline \multicolumn{5}{|c|}{ Lymphatic invasion, $\mathrm{n}$} \\
\hline Negative & 49 & 24 & 25 & 0.018 \\
\hline Positive & 126 & 86 & 40 & \\
\hline \multicolumn{5}{|c|}{ Venous invasion, $\mathrm{n}$} \\
\hline Negative & 58 & 28 & 30 & 0.005 \\
\hline Positive & 117 & 82 & 35 & \\
\hline
\end{tabular}

\section{Discussion}

SOX9 was first identified as a key regulator of cartilage and male gonadal development (11). Mutation or abnormal expression of the $S O X$ gene contributes to many diseases, such as campomelic dysplasia and autosomal sex reversal (2). Recently, there have been reports of a correlation between SOX9 expression and clinical outcome in some cancer types. SOX9 was found to be up-regulated in several tumour types, such as carcinomas of the lung, prostate, pancreas, liver, biliary tract, colorectum, and stomach (3-9). Among gastrointestinal types of cancer, SOX9 protein was detected as being strongly expressed in colorectal carcinoma (34\%) (8) and gastric carcinoma (34\%) (9). In the present series, strong SOX9 expression was seen in $32 \%$ of ESCCs, in accordance with other types of gastrointestinal cancer.

Concerning the significance of SOX9 expression in digestive tract cancer, several studies have examined SOX9 expression and various clinicopathological parameters and prognosis as follows. In pancreatic carcinoma, SOX9 

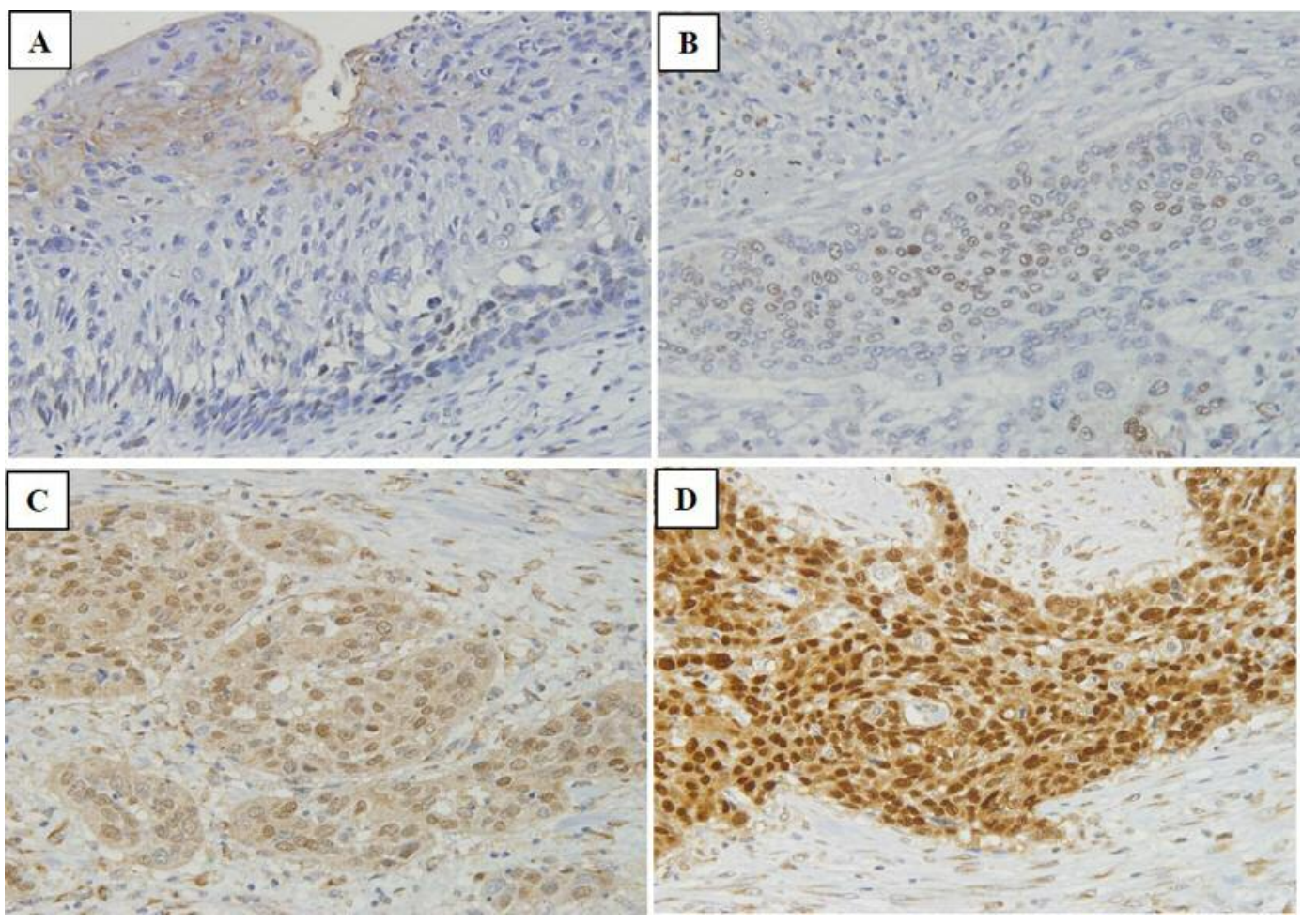

Figure 1. Nuclear expression of sex-determining region Y-box 9 (SOX9) protein in oesophageal squamous cell carcinoma. A: Negative nuclear expression of SOX9. B: Weak nuclear expression of SOX9. C: Moderate nuclear expression of SOX9. D: Strong nuclear expression of SOX9. Original magnification, $\times 200$.

expression was significantly associated with distant metastasis and worse survival (5); in hepatocellular carcinoma, SOX9 expression was significantly associated with higher tumour stage and grade, and lower 5-year overall survival (6); in cholangiocarcinoma, SOX9 expression was significantly associated with biliary infiltration and poor survival (7); in colorectal carcinoma, SOX9 expression was found to be related to tumour histological type and worse overall survival (8); and in gastric carcinoma, SOX9 expression was significantly associated with tumour invasion, lymph node metastasis, and advanced stage (9).

In the present study, SOX9 expression was significantly associated with depth of tumour invasion, advanced stage, lymphatic and venous invasion, and poor overall survival. Taken together, SOX9 may be related to malignant properties such as proliferation, invasion, metastasis, and worse prognosis of digestive tract cancer.

Recent studies showed that SOX9 controls cell fate during the development of a broad range of tissues generally, inhibits apoptosis and promotes proliferation, invasion, and metastasis of human cancer cells $(12,13)$. The mechanisms underlying these phenomena were explained as follows. Firstly, SOX9 is required for tumour formation in a

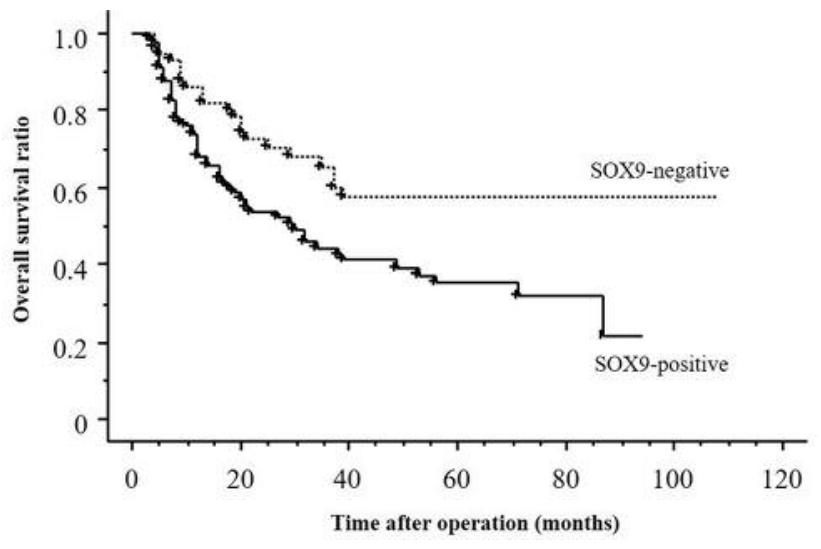

Figure 2. Overall postoperative survival curves according to nuclear expression of sex-determining region Y-box 9 (SOX9) protein. Survival was significantly poorer for patients with SOX9-positive disease compared to those who had SOX9-negative disease ( $p=0.008)$.

WNT/beta-catenin signalling-dependent manner, which then promotes cancer stemness and inhibits differentiation. Secondly, SOX9 controls adhesion and extracellular matrix and cytoskeleton remodelling. Finally, SOX9 promotes 
in vivo $32: 835-838(2018)$

Table II. Univariate and multivariate analyses of survival in patients with oesophageal squamous cell carcinoma.

\begin{tabular}{lccccc}
\hline Factor & Comparison & Univariate $p$-Value & Hazard ratio & 95\% Confidence interval & Multivariate $p$-Value \\
\hline pT & pT1, $2 v s . \mathrm{pT} 3,4$ & $<0.001$ & 0.370 & $0.181-0.758$ & 0.007 \\
pN & pN0 $v s . \mathrm{pN} 1$ & $<0.001$ & 1.386 & $0.509-3.777$ & 0.523 \\
pM & pM0 $v$ s. pM1 & $<0.001$ & 0.573 & $0.326-1.009$ & 0.054 \\
Stage & I, II $v s$. III, IV & $<0.001$ & 0.319 & $0.116-0.879$ & 0.027 \\
Lymphatic invasion & Negative $v s$. positive & $<0.001$ & 0.931 & $0.297-2.920$ & 0.902 \\
Venous invasion & Negative $v s$. positive & $<0.001$ & 0.667 & $0.297-2.920$ & 0.225 \\
SOX9 & Negative $v s$. positive & 0.010 & 0.934 & $0.546-1.598$ & 0.806 \\
\hline
\end{tabular}

SOX9: Sex-determining region Y-box 9.

oncogene-expressing cells to develop into invasive tumours (13). In patients with ESCC in the present study, SOX9 expression had prognostic value that correlated with tumour invasion, in accordance with the latest research data.

In conclusion, SOX9 expression had a prognostic value in univariate analysis that correlated with tumour invasion, although it was not an independent prognostic factor in multivariate analysis. Evaluation of SOX9 expression might be partially useful for determining malignant properties in patients with ESCC.

\section{Acknowledgements}

This study was supported by a Grant in Aid for Scientists for HO from the Ministry of Education, Culture, Sports, Science and Technology of Japan (Grant number 15K10107).

\section{References}

1 Tachimori Y, Ozawa S, Numasaki H, Fujishiro M, Matsubara H, Oyama T, Shinoda M, Toh Y, Udagawa H, Uno $\mathrm{T}$ and Registration Committee for Esophageal Cancer of the Japan Esophageal Society: Comprehensive Registry of Esophageal Cancer in Japan, 2009. Esophagus 13: 110-137, 2016.

2 Wagner T, Wirth J, Meyer J, Zabel B, Held M, Zimmer J, Pasantes J, Bricarelli FD, Keutel J, Hustert E, Wolf U, Tommerup N, Schempp W and Scherer G: Autosomal sex reversal and campomelic dysplasia are caused by mutations in and around the SRY-related gene SOX9. Cell 79: 1111-1120, 1994.

3 Zhou CH, Ye LP, Ye SX, Li Y, Zhang XY, Xu XY and Gong LY: Clinical significance of SOX9 in human non-small cell lung cancer progression and overall patient survival. J Exp Clin Cancer Res 31: 18, 2012.

4 Zhong WD, Qin GQ, Dai QS, Han ZD, Chen SM, Ling XH, Fu X, Cai C, Chen JH, Chen XB, Lin ZY, Deng YH, Wu SL, He $\mathrm{HC}$ and Wu CL: SOXs in human prostate cancer: implication as progression and prognosis factors. BMC Cancer 12: 248, 2012.

5 Xia S, Feng Z, Qi X, Yin Y, Jin J, Wu Y, Wu H, Feng Y and Tao M: Clinical implication of SOX9 and activated AKT expression in pancreatic ductal adenocarcinoma. Med Oncol 32: 358, 2015.
6 Guo X, Xiong L, Sun T, Peng R, Zou L, Zhu H, Zhang J, Li H and Zhao J: Expression features of SOX9 associate with tumor progression and poor prognosis of hepatocellular carcinoma. Diagn Pathol 7: 44, 2012.

7 Matsushima H, Kuroki T, Kitasato A, Adachi T, Tanaka T, Hirabaru M, Hirayama T, Kuroshima N, Hidaka M, Soyama A, Takatsuki M, Kinoshita N, Sano K, Nishida N and Eguchi S: SOX9 expression in carcinogenesis and its clinical significance in intrahepatic cholangiocarcinoma. Dig Liver Dis 47: 10671075, 2015.

8 Lü B, Fang Y, Xu J, Wang L, Xu F, Xu E, Huang Q and Lai M: Analysis of SOX9 expression in colorectal cancer. Am J Clin Pathol 130: 897-904, 2008

9 Zhou CJ, Guo JQ, Zhu KX, Zhang QH, Pan CR, Xu WH, Wang $\mathrm{HJ}$ and Liu B: Elevated expression of SOX9 is related with the progression of gastric carcinoma. Diagn Cytopathol 39: 105-109, 2011.

10 Sobin LH and Wittwkind CH: TNM Classification of Malignant Tumors, International Union Against Cancer, Sixth Edition. New York: John Wiley \& Sons, 2002.

11 Foster JW, Dominguez-Steglich MA and Guioli S, Kwok C, Weller PA, Stevanović M,Weissenbach J, Mansour S, Young ID, Goodfellow PN, Brook D and Schafer AJ: Campomelic dysplasia and autosomal sex reversal caused by mutations in an SRY-related gene. Nature 372: 525-530, 1994.

12 Kadaja M, Keyes BE, Lin M, Pasolli HA, Genander M, Polak L, Stokes N, Zheng D and Fuchs E: SOX9: a stem cell transcriptional regulator of secreted niche signaling factors. Genes Dev 28: 328-341, 2014.

13 Larsimont JC, Youssef KK, Sánchez-Danés A Sukumaran V, Defrance M, Delatte B, Liagre M, Baatsen P, Marine JC, Lippens S, Guerin C, Del Marmol V, Vanderwinden JM, Fuks F and Blanpain C: SOX9 controls self-renewal of oncogene targeted cells and links tumor initiation and invasion. Cell Stem Cell 17: 60-73, 2015. 